\title{
DESTRUIÇÃO DE FORÇAS PRODUTIVAS E O REBAIXAMENTO DA FORMAÇÃO DA CLASSE TRABALHADORA: O CASO DA REFORMA E DA BNCC DO ENSINO MÉDIO ${ }^{1}$
}

\author{
DESTRUCCIÓN DE FUERZAS PRODUCTIVAS Y EL REBAJAMIENTO DE LA \\ FORMACIÓN DE LA CLASE TRABAJADORA: EL CASO DE LA REFORMA Y DE LA \\ BNCC DE LA ESCUELA SEUNDARIA
}

\section{DESTRUCTION OF PRODUCTIVE FORCES AND THE REDUCTION OF SCHOOL EDUCATION OF THE WORKING CLASS: THE CASE OF REFORM AND BNCC OF HIGH SCHOOL}

\author{
DOI: http://dx.doi.org/10.9771/gmed.v11i1.32000
}

Celi Nelza Zulke Taffarel2 ${ }^{2}$

José Arlen Beltrao 3

\begin{abstract}
Resumo: Este texto objetiva explicar os nexos e relações entre a destruição de forças produtivas e o rebaixamento da formação escolar dos filhos da classe trabalhadora. Discute os elementos centrais e as principais contradições do imperialismo e analisa as mudanças fundamentais promovidas pela lei n. 13.415/2017 e a BNCC do ensino médio, apontando os nexos e relações com o processo de destruição de forças produtivas. Foi possível constatar que esses dispositivos acentuam a tendência de esvaziamento científico do currículo escolar e de desqualificação dos jovens trabalhadores ainda no seu processo de escolarização básica. Além disso, integram o movimento de ofensiva do imperialismo no Brasil, de destruição dos serviços públicos e de forças produtivas.
\end{abstract}

Palavras-chave: Reforma do ensino médio. BNCC. Destruição de forças produtivas

Resumen: Este texto objetiva explicar los nexos y relaciones entre la destrucción de fuerzas productivas y el descenso de la formación escolar de los hijos de la clase trabajadora. Discute los elementos centrales y las principales contradicciones del imperialismo y analiza los cambios fundamentales promovidos por la ley n. 13.415/2017 y la BNCC de la escuela secundaria, apuntando a los nexos y relaciones con el proceso de destrucción de fuerzas productivas. Es posible constatar que estos dispositivos acentúan la tendencia de vaciamiento científico del currículo escolar y de descalificación de los jóvenes trabajadores aún en su proceso de escolarización básica. Además, integran el movimiento de ofensiva del imperialismo en Brasil, de destrucción de los servicios públicos y de fuerzas productivas.

Palabras clave: Reforma de escuela secundaria. BNCC. Destrucción de fuerzas productivas.

Abstract: This text aims to explain the links and relations between the destruction of productive forces and the reduction of school education of the working class children. It discusses the central elements and main contradictions of imperialism and analyzes the fundamental changes promoted by law n. 13.415/2017 and the BNCC of high school, pointing out the links and relations with the process of destruction of productive forces. It was possible to verify that these devices accentuate the tendency of scientific emptying of the school curriculum and of disqualification of the young workers still in their process of basic schooling. In addition, they integrate the imperialist offensive movement in Brazil, the destruction of public services and productive forces.

Key words: High school reform. BNCC. Destruction of productive forces. 


\section{Considerações iniciais}

Este trabalho objetiva explicar os nexos e relações entre a destruição de forças produtivas e o rebaixamento da formação escolar dos filhos da classe trabalhadora, resultado, principalmente, da restrição/negação do acesso ao conhecimento científico. Para isso, explicitar-se-á como esse fenômeno se manifesta a partir da análise da reforma do ensino médio e da Base Nacional Comum Curricular (BNCC) deste mesmo nível de ensino.

A restrição ou a negação do acesso ao conhecimento científico constituem-se em uma das principais contradições presentes na educação escolar pública (SAVIANI; DUARTE, 2012). Em consequência, observa-se que a função social da escola pública de socializar os conhecimentos mais desenvolvidos e necessários à elevação do padrão cultural da classe trabalhadora, oferecendo assim condições para o desenvolvimento das diversas potencialidades dos estudantes, não vem se realizando a contento, ampliando possibilidades humanas de se conhecer e compreender o mundo (expressas nas diversas objetivações humanas historicamente produzidas) e a realidade (expressa naquilo que o conjunto dos trabalhadores se apropriou efetivamente), ocasionando em determinados momentos, na educação formal, o esvaziamento dos conteúdos escolares (DUARTE, 2004).

Para abordar essas questões, no primeiro tópico serão discutidos os elementos centrais e as principais contradições do imperialismo, particularmente a tendência de destruição de forças produtivas. No segundo tópico serão analisadas as mudanças fundamentais promovidas pela lei n. 13.415/2017 e pela BNCC do ensino médio, apontando os nexos e relações com o processo de destruição de forças produtivas. Por fim serão apontados os desafios relacionados à disputa pelo projeto de formação escolar vinculado à classe trabalhadora.

\section{Imperialismo: destruição de forças produtivas, regressão social e apropriação da educação pública}

No decurso do seu desenvolvimento, o capitalismo vivenciou no final do século XIX e início do século XX mudanças substantivas que resultaram na conversão do capitalismo concorrencial em imperialismo (LÊNIN, 2007). Destacamos que diferentemente do que ocorria no primeiro estágio de desenvolvimento deste modo de produção, onde as crises e os problemas de rentabilidade do capital eram, quase sempre, resolvidos com a abertura ou conquistas de novos mercados (MONTORO, 2014); em seu estágio imperialista, com os mercados integrados, com a preponderância dos oligopólios e do capital financeiro (LÊNIN, 2007), para destravar os processos de acumulação, recorre-se, sistematicamente, à destruição de forças produtivas (MONTORO, 2014). Portanto, a tendência de destruição de forças produtivas constitui-se em elemento fundamental para se explicar os fenômenos próprios do imperialismo e as demais questões vinculadas a esse processo.

A raiz deste problema encontra-se no processo de reprodução ampliada do capital, mais especificamente nos conflitos entre os capitalistas objetivando uma melhor competitividade e, por conseguinte, apropriação de uma fração maior da mais valia total. Em outros termos, a pugna entre os 
capitais concorre para a busca do aumento da produtividade, quase sempre associada a uma crescente mecanização ou agregação tecnológica à produção, que por sua vez resultam em uma maior proporção de capital constante em relação ao capital variável. Como a composição do capital está relacionada à rentabilidade, essa tendência de aumento do capital constante significa, na prática, menor rentabilidade. $\mathrm{O}$ decréscimo da rentabilidade (taxa lucro), fora apontada por Marx como sendo "a lei mais importante da sociedade moderna". Como toda tendência, a queda da taxa de lucro pode ser evitada, entretanto, a sua contenção ou reversão, mesmo que temporária, se tornam cada vez mais difíceis e, acima de tudo, com impactos sociais mais sérios (MONTORO, 2018).

No atual estágio de desenvolvimento do capitalismo, recorre-se, frequentemente, à destruição de forças produtivas para a superação das dificuldades de rentabilidade e valorização dos capitais. Nesse caso, cabe esclarecer que o significado de forças produtivas adotado nesse trabalho não se confunde com produtividade, muito menos é reduzido a uma questão técnica, pois se trata de uma categoria social. Somente assim é possível compreender porque os avanços técnicos não asseguram um desenvolvimento efetivo das forças produtivas e a melhora da condição de vida da maioria.

Montoro (2014, p.60-61, tradução nossa) destaca que "uma coisa é a formulação de forças produtivas do trabalho, associada estritamente a sua capacidade técnica de produção, de forma a-social e, portanto, relacionada exclusivamente com a produtividade. Outra coisa, bem diferente, é a categoria econômica e, portanto, social de forças produtivas". Nessa acepção, a categoria forças produtivas é concebida para além de suas questões técnicas relacionadas à produtividade; considera-se as combinações estabelecidas entre trabalho vivo e os meios de produção, quer dizer, as relações de produção onde essas forças produtivas são postas em funcionamento. Segundo Montoro (2014, p. 63, tradução nossa), “o desenvolvimento das forças produtivas condiciona as relações de produção e estas, que, portanto, dependem daquelas, por sua vez também tem influência sobre as forças produtivas. O vínculo entre ambas é dialético, dinâmico, está em evolução permanente, com tensionamentos e contradições.

Marx, ao longo de sua obra, abordou essas duas categorias de modo dialético. Em A Miséria da Filosofia, por exemplo, afirmou que

As relações sociais estão intimamente ligadas às forças produtivas. Adquirindo novas forças produtivas, os homens transformam o seu modo de produção e, ao transformálo, alterando a maneira de ganhar a sua vida, eles transformam todas as suas relações sociais. O moinho movido pelo braço humano nos dá a sociedade com o suserano; o moinho a vapor dá-nos a sociedade com o capitalista industrial (MARX, 2009, p. 125).

Em a Contribuição à crítica da economia política, Marx sustentou que:

[...] na produção social da própria existência, os homens entram em relações determinadas, necessárias, independentes de sua vontade; essas relações de produção correspondem a um grau determinado de desenvolvimento de suas forças produtivas materiais. A totalidade dessas relações de produção constitui a estrutura econômica da sociedade, a base real sobre a qual se eleva uma superestrutura jurídica e política e à qual correspondem formas sociais determinadas de consciência [...] Em uma certa etapa de seu desenvolvimento, as forças produtivas materiais da sociedade entram em contradição com as relações de produção existentes, ou, o que não é mais que sua expressão jurídica, com as relações de propriedade no seio das quais elas se haviam desenvolvido até então. De formas evolutivas das forças produtivas que eram, essas relações convertem-se em entraves (MARX, 2008, p. 47-48). 
A lógica que impera nas relações de produção capitalista, em determinadas circunstâncias, dentre elas a ausência de rentabilidade suficiente ou desejada, leva à inutilização da capacidade produtiva da sociedade, em outras palavras, as forças produtivas entram em contradição com as relações de produção. $\mathrm{O}$ desemprego e o fechamento de fábricas são exemplos que expressam essa situação. A partir destes casos, é possível inferir que as forças produtivas carregam uma expectativa de produtividade, constituem em possibilidade, que será efetivada ou não a depender das relações de produção. Portanto, "as forças produtivas, em sua inter-relação com as relações de produção (graças as quais adquirem seu caráter social, histórico), não consistem na produtividade, mas no aproveitamento social das potencialidades que, hipoteticamente, pode trazer tal produtividade" (MONTORO, 2014, p. 60-61, tradução nossa). Isso ocorre porque, segundo Montoro (2018), a força motriz do capitalismo é o lucro, é a rentabilidade.

As recorrentes crises econômicas vivenciadas nas últimas décadas, expressões dessas dificuldades de valorização do capital, vêm sendo resolvidas, preferencialmente, através da destruição de forças produtivas, caracterizadas por ações que têm como consequência a desindustrialização, os desinvestimentos, as especulações, a devastação da natureza, a desvalorização em massa de mercadorias, equipamentos e instalações produtivas (HARVEY, 2016), as guerras frequentes, as privatizações e o desmantelamento de direitos sociais e trabalhistas (MONTORO, 2014).

O principal componente das forças produtivas, a força de trabalho, é quem mais sofre os ataques destrutivos. A centralidade desse movimento está na redução do valor da força de trabalho, que consiste em destruição de força produtiva, mas favorece o aumento da taxa de mais-valia que, por sua vez, constitui-se em uma contramedida à tendência decrescente da taxa de lucro.

Em geral, a redução do valor da força de trabalho pode ocorrer de modo direto, quando se diminui a remuneração ou se implementa medidas que em última instância tem esse fim, como a desregulação das proteções trabalhistas e a legalização ou o consentimento dos diferentes tipos de subemprego; ou de modo indireto, quando se reduz o poder de compra do trabalhador, seja pela depreciação decorrente da inflação ou através de privatizações de serviços públicos, implicando em novas ou maiores tarifas, como por exemplo em educação, saúde, água, esgoto, energia elétrica, etc. (MONTORO, 2014), e para isto o imperialismo conta com a atuação das organizações transnacionais, sobretudo o Fundo Monetário Internacional (FMI), que conduzem os processos necessários para que as referidas políticas se materializem, numa espécie de estratégia política global.

Os ajustes fundomonetarista são respostas oferecidas às crises anteriores, contudo, são também, via de regra, as causas das crises posteriores, que por sua vez são ainda maiores. Em resumo, as medidas adotadas visam a recomposição das condições que permitam a valorização do capital, destravando os obstáculos para a sua rentabilidade, e a abertura de novos espaços para a acumulação privada. Contudo, os mesmos problemas são encontrados em futuro próximo. Por esse motivo, Montoro (2014) denomina esse processo de "saída à diante" (crise $\rightarrow$ ajuste $\rightarrow$ crise).

Com efeito, a política de ajustes do FMI se universalizou a partir da década de 1980. Sendo que no seu receituário, se destacam (a) as privatizações, defendidas com o mantra de maior eficiência das empresas privadas; (b) a desregulação dos mercados, incluindo várias outras medidas como liberalização de 
investimentos estrangeiros, redução de impostos, quebra das barreiras de importação, etc.; e a (c) garantia dos direitos de propriedade (MONTORO, 2014).

Nessa ofensiva, os capitalistas buscam a privatização de empresas ou setores que já são rentáveis, com isso a promessa de eficiência, que nesse caso está geralmente vinculada à rentabilidade, quase sempre, se confirma (frequentemente associada à redução de salários, da qualidade etc.). Como consequência, constata-se que as privatizações promovem destruição econômica direta (liquidação de segmentos não rentáveis e dos empregos correspondentes), alterações nas orientações das atividades (agora guiadas fundamentalmente pela rentabilidade), perda de controle da atividade (não só do ponto de vista do poder público, mas do próprio capital nacional, tendo em vista a entrada e poder do capital estrangeiro), além disso, normalmente, escondem operações puramente especulativas (em alguns casos apenas para liquidar com a atividade em questão) (MONTORO, 2014).

As privatizações não são simplesmente um fato jurídico, consistem na mudança de propriedade ou de gestão das empresas ou serviços anteriormente públicos que passam a ser privados. A mudança de titularidade da propriedade (ou da gestão) é só uma forma que toma um processo social, com dimensões econômicas e políticas muito importantes, que busca abrir novos espaços de rentabilidade para a acumulação privada, assim como desvalorizar a força de trabalho através da redução indireta do salário [...] (MONTORO, 2014, p. 389, tradução nossa).

Tanto as privatizações quanto os ataques diretos às regulamentações e proteções da força de trabalho são aplicados sob o disfarce de políticas de austeridade, que encontram nos ajustes econômicos a principal via para sua consecução.

Nesse sentido, o imperialismo, declaradamente, busca impor uma desregulamentação universal e total, uma flexibilização ilimitada, que vai muito além do mercado de trabalho, garantindo, portanto, uma liberdade plena em escala mundial para o capital, de modo que tanto as mercadorias quanto os capitais não sejam limitados por quaisquer tipos de barreiras (PAULO NETTTO; BRAZ, 2012). Isso se justifica porque os trabalhadores conquistaram regulamentações não só no mercado de trabalho - como o descanso semanal, o limite de carga horária, o auxílio-doença, o salário mínimo, etc., mas também em outros mercados, como o de alimentos (normas de ingredientes, conservação, limites para uso de agrotóxicos, etc.), o de saúdedoença (obrigações de cobertura, uso de protocolos, etc.), o educacional (carga horária, conteúdo, critérios para contração de professores - formação por exemplo, etc.) que, em última instância, oferecem garantias aos trabalhadores, mas, por outro lado, impõem limites à produção e comercialização de diferentes mercadorias (MONTORO, 2014).

As consequências deste processo são a regressão social, expressa, dentre outras coisas, nos elevadíssimos índices de desemprego no mundo (201 milhões de pessoas) (OIT, 2017) e no Brasil (14 milhões de pessoas) (PERET, 2017), e a crescente concentração de renda e capitais em todas as regiões do planeta $^{4}$ (OXFAM, 2017).

Com isso, a contradição entre os incalculáveis e relevantes avanços científicos e tecnológicos alcançados no último século e a decadência na condição de vida da maioria da população mundial, ou seja, a contradição entre as possibilidades e a realidade fica cada vez mais manifesta e expõe a face regressiva do imperialismo. Ao mesmo tempo, segundo Harvey (2016), demonstra a impossibilidade do capital empregar 
as suas forças produtivas em favor do bem-estar comum, "em razão de seu comprometimento com as relações de classe vigente e seus mecanismos associados de reprodução, dominação e controle de classe [...]" (HARVEY, 2016, p. 93).

É possível identificar esse processo destrutivo inclusive na educação. O interesse nessa área se justifica, essencialmente, por ela (a) consistir num componente do salário indireto, por (b) representar possibilidade de espaço para a reprodução do capital, através de diferentes formas de privatizações, e por (c) favorecer a implementação do projeto pedagógico hegemônico. Em decorrência, "[...] se nega o direito à educação [às classes populares], configurando esta como um negócio a mais e, portanto [...] uma educação de segunda [...]" (MONTORO, 2014, p. 463, inclusão nossa entre colchetes, tradução nossa).

Além disso, em relação à valorização do capital, é estratégico reduzir os custos e o tempo de formação, bem como simplificá-la no que for possível, conforme destacado por Marx, já que "[...] a desvalorização relativa da força de trabalho, decorrente [...] da redução dos custos de aprendizagem, redunda, para o capital, em acréscimo imediato de mais-valia, pois, tudo o que reduz o tempo de trabalho necessário para reproduzir a força de trabalho aumenta o domínio do trabalho excedente" (MARX, 2014, p. 405).

Do ponto de vista da classe dominante, as ideias pedagógicas presentes em seus projetos educacionais se estruturam em torno de dois eixos centrais, a produtividade e a passividade, os quais se articulam visando que os sujeitos "se percebam como capital humano, mercadoria força de trabalho, em busca de aprimoramento de suas capacidades produtivas e de oportunidades de 'empregabilidade" (MOTTA; LEHER; GAWRYSZEWSKI, 2018, p. 313).

Nesse contexto, observa-se a desvalorização da transmissão do conhecimento científico, a diluição do papel da escola em transmitir esse conhecimento e uma valoração negativa do ato de ensinar. Por outro lado, investe-se num discurso que tenta convencer que mais importante do que se apropriar dos conhecimentos é aprender a aprendê-los, mais importante que acumular conhecimento seria desenvolver habilidades e competências exigidas na vida cotidiana e laboral (DUARTE, 2004).

Sustentadas por essas ideias, reformas educacionais vêm sendo realizadas em todo o mundo, com colaboração destacada do FMI, do Banco Mundial (BM) e da Organização das Nações Unidas para a Educação, a Ciência e a Cultura (Unesco), através de produção e divulgação de orientações que subsidiem essas reformas ou ingerindo diretamente na política dos países.

Além das questões mais relacionadas ao caráter pedagógico da educação, nas duas últimas décadas, esses organismos passaram a advogar por uma maior participação de entes não estatais no oferecimento da educação pública, bem como pela implementação de gestões com inspiração empresariais e de formas diversificadas de privatização da educação pública (WORL BANK, 2011; UNESCO, 2008). A intenção é constituir sistemas educacionais públicos híbridos, com nova concepção e estruturação, possibilitando a participação do Estado e de entes não estatais (empresas, organização sociais, etc.) expandindo espaço para a reprodução do capital.

Em síntese, diante das dificuldades crescentes em manter a taxa de lucro em padrões desejados, os capitalistas recorrem a diversos meios para destravar os processos de acumulação, inclusive promovendo 
destruição econômica e submetendo a maioria da população à regressão social. As medidas destrutivas se concentram em dois eixos inter-relacionados: (i) a redução do valor da força de trabalho, associada à liquidação de direitos e conquistas sociais e democráticas; (ii) apropriação de patrimônio e de serviços públicos, dentre eles a educação, através das diferentes formas de privatização, visando ampliar os espaços para a reprodução do capital.

\section{A reforma e a BNCC do ensino médio: radicalização da formação unilateral e avanço da privatização}

Desde o golpe parlamentar-jurídico-midiático que destituiu a ex-presidenta Dilma Rousseff, o novo bloco no poder ${ }^{5}$ (BOITO JR, 2018) se empenhou em realizar reformas e implementar uma série de medidas, como as alterações nas leis trabalhistas, as modificações nas regras de exploração de petróleo, a instituição do teto dos gastos públicos (emenda constitucional n. 95), as alterações nas regulamentações ambientais, o plano de novas concessões e privatizações, as mudanças nas políticas das empresas públicas, a terceirização ilimitada e a intenção de reformar a previdência pública. O bloco no poder executa uma agenda regressiva, com forte ofensiva do capital sobre os trabalhadores, e restaura a hegemonia da política fundomonetarista pura e dura.

$\mathrm{Na}$ educação, apesar de forte oposição popular ${ }^{6}$, foi aprovada a lei n. 13.415/2017 (BRASIL, 2017), que promoveu a reestruturação no ensino médio. Durante o célere processamento da Medida Provisória (MP n. 746/2016) que deu origem a referida lei, o Ministério da Educação (MEC) elegeu como interlocutores preferenciais representantes do setor empresarial, por outro lado, restringiu o diálogo e preteriu as reivindicações dos sindicatos ligados à educação, do movimento estudantil e das entidades científicas da área.

A BNCC (BRASIL, 2018a) foi outro dispositivo educacional relevante aprovado nesse período. A equipe técnica que conduzia os trabalhos da BNCC foi alterada e conselheiros do Conselho Nacional de Educação (CNE) foram substituídos. A relação estabelecida com os profissionais da educação e a juventude, durante o processo de discussão da $3^{a}$ versão do documento, foi conflituosa ${ }^{7}$. A versão final da BNCC foi aprovada com profundas transformações em relação às versões produzidas durante o governo Dilma Rousseff.

Segundo o MEC (BEZERRA FILHO, 2016, p. 10), as políticas educacionais implementadas pelo novo bloco no poder são inspiradas e visam alinhar “[...] as premissas da presente proposta às recomendações do Banco Mundial e do Fundo das Nações Unidas para Infância - Unicef'. Esse posicionamento sugere que a reforma e a BNCC do ensino médio integram o movimento de reformas supracitadas e atendem aos interesses hegemônicos.

Ao analisar a reforma do ensino médio, Beltrão (2019) constatou que as medidas previstas nesta reforma concorrem para a redução da formação básica comum, o estreitamento curricular, a flexibilização da oferta de ensino, a possibilidade do ensino à distância, a viabilidade de parcerias com entes não-estatais, 
a especialização precoce e a instituição de percursos escolares diferenciados, que por sua vez tendem a aprofundar a distribuição desigual do conhecimento.

A carga horária destinada à formação básica comum, aquela que será referenciada na BNCC, foi drasticamente reduzida. No modelo anterior, era determinado um mínimo de 2.400 horas. A lei n. 13.415/2017 normatizou a carga horária máxima (1.800 horas), sem, contudo, definir um tempo mínimo para a formação básica. Portanto, na melhor das hipóteses, os jovens terão uma redução de $25 \%$ na formação, o que poderá, dependendo as circunstâncias, ampliar essa distorção.

Na prática, com essa medida, opera-se a retirada de conhecimento e o esvaziamento da formação escolar da juventude. Por outro lado, ao encaminhar o estudante para uma área de concentração ou formação profissional, antecipa-se a especialização deste jovem, em um processo formativo pobre e limitado. O tempo de formação profissional, nesse caso, é diminuto. Nessas circunstâncias, as formações profissionais estarão, tendencialmente, voltadas para o trabalho simples e de baixo valor agregado. Essas constatações indicam que o novo ensino médio tende a promover uma especialização precoce sob uma base (formação geral) precária/reduzida, em outros termos, apontam para uma formação unilateral radicalizada. O rebaixamento da formação básica pode significar a interposição de mais obstáculos para os jovens provenientes das classes populares acessar o ensino superior, expediente presente em quase toda a história do ensino médio, que a atual reforma revigora.

A nova estruturação do ensino médio, a partir das determinações presentes na BNCC e nas Diretrizes Curriculares Nacionais do Ensino Médio (DCNEM) de 2018 (BRASIL, 2018b), prevê dois tipos de componentes curriculares. Nesse caso, têm-se os considerados essenciais e detentores de prestígio e maior espaço no currículo, notadamente a língua portuguesa e a matemática. Em contrapartida, os demais componentes, que integravam o currículo anterior, perderam a condição de obrigatórios e o status de componente curricular não está assegurado, visto que agora são considerados estudos e práticas e seus conhecimentos podem ser diluídos nos demais componentes curriculares ou ofertados de maneira diversa.

Ademais, a BNCC do ensino médio faz a defesa do ensino pautado na pedagogia das competências, realça práticas de ensino-aprendizagem utilitárias, pragmáticas e o conhecimento tácito. Em sua proposta, o conhecimento científico é considerado elemento secundário, já que assume a função de meio para desenvolver as competências e habilidades.

Conforme destacam Ramos e Frigotto (2016), essas medidas atendem a uma lógica economicista e pragmática:

A contra-reforma é expressão do pensamento conservador, valendo-se de uma lógica
economicista e pragmática expressiva de nosso capitalismo dependente, em um tempo
de hegemonia neoliberal e cultura pós-moderna; a cultura do fragmento, do imediato, do
utilitário e do enxuto. Trata-se de uma política que liofiliza a educação básica retirando-
lhe conteúdo de formação científica e ético-política que se esperaria numa sociedade que
tem as pessoas e não o mercado como a razão da política pública (RAMOS; FRIGOTTO,
2016, p. 37).

Além das mudanças pedagógicas-didáticas, a lei n. 13.415/2017 e a BNCC do ensino médio concorrem para acentuar tendências já em curso no âmbito da gestão escolar. Mais especificamente, ao permitir que itinerários formativos sejam ofertados por outras entidades (art. $36, \S 8^{\circ}$ da LDB), que parte 
do currículo possa ser cursado em instituições de educação à distância conveniadas (art. $36, \mathbb{1} 11^{\circ}$ da LDB), ao regulamentar a contratação de professores com notório saber (art. 61, inciso IV da LDB), ao fragmentar e flexibilizar o currículo e reduzir o número de componentes obrigatórios (art. 36 da LDB), criam-se condições ainda mais favoráveis para que os processos privatizantes se potencializem.

Sobre isto, Beltrão e Taffarel (2017) demonstraram que cresce no Brasil a privatização da educação pública, especialmente a privatização endógena, ou seja, por dentro das redes, via parcerias público-privadas. Segundo os autores, três modelos se destacam no caso brasileiro "[...] (1) A venda de insumos, produtos e serviços; (2) A gestão de escolas do sistema público de modo compartilhado, sem contrapartida financeira imediata/direta; (3) A gestão/administração direta da escola ou da rede de ensino, com contrapartida financeira".

Todas essas formas de privatização são favorecidas pelas medidas descritas no parágrafo anterior. Já que,

Ao reduzir normas e barreiras, diferentes rearranjos serão possíveis, dando mais liberdade às empresas e fundações. Algumas poderão se especializar em oferecer determinado itinerário formativo, muitas desenvolverão programas on-line, outras assumirão a gestão das escolas ou redes, optando por arranjos curriculares de menor custo, dentre várias combinações possíveis (BELTRÃO; TAFFAREL, 2018, p. 597).

Não por acaso, o capital financeiro vem se aproximando cada vez mais da educação, interessado nessas oportunidades que se abrem (OLIVEIRA, 2009). Esse movimento vem contribuindo para a formação de verdadeiros impérios, como é o caso da Kroton, que sinaliza forte investimento na educação básica ${ }^{8}$.

É possível constatar que a reforma e a BNCC do ensino médio acentuam a tendência de esvaziamento científico do currículo escolar, de desqualificação dos jovens trabalhadores ainda no seu processo de escolarização básica e de consolidação deste nível de ensino como etapa terminal para a maioria dos filhos da classe trabalhadora, além de oferecerem melhores condições para os processos de privatização da educação básica.

É necessário acrescentar que o ideário pedagógico hegemônico, associado à reforma e à BNCC do ensino médio, contribui com a disseminação de práticas e ideias que corroboram com a conformação social em relação à intensificação da precarização, da exploração (MOTTA; LEHER; GAWRYSZEWSKI, 2018), do desemprego sistemático, bem como da naturalização das diferentes formas de subemprego.

Isto posto, é importante ressaltar que essa política educacional é aprofundada num contexto de redução da rentabilidade do capital na economia nacional e da elevação dos salários dos brasileiros nos últimos anos (PINTO et. al., 2017). Diante deste quadro, percebe-se que o empresariado brasileiro opta por reduzir os custos da qualificação da força de trabalho, simplificando-a e alinhando-a com as demandas contemporâneas, ao mesmo tempo, opta por ampliar o exército de reserva, visando à depreciação dos salários, mesmo que isso signifique um aprofundamento da dependência e subordinação da nossa economia.

Deste modo, constata-se que a atual reforma e a BNCC do ensino médio são dispositivos que integram o movimento de ofensiva do imperialismo no Brasil, de destruição dos serviços públicos (dentre 
eles a educação) e de forças produtivas. Dentre as consequências, os jovens brasileiros, estudantes das escolas públicas, estarão sujeitos a uma maior intensificação da exploração.

\section{Considerações finais}

Diante da situação aberta com a reforma do ensino médio, que perspectiva uma formação ainda mais limitada e restrita para nossos jovens, num quadro de regressão dos direitos democráticos e sociais, e de destruição sistemática de forças produtivas, todos são chamados a se posicionar em resposta à questão que emerge deste contexto: resistir ou se adaptar à proposta do novo ensino médio e da BNCC?

Aos que lutam pela elevação do padrão cultural da classe trabalhadora, pela construção de uma escola que mire uma formação omnilateral e que perspectivam superar a sociedade de classes, caberá resistir.

Se por um lado a correlação de forças, praticamente em todos os campos de disputa, inclusive na educação, vem se mostrando cada vez mais desfavorável à classe trabalhadora. Por outro, o problema concreto de alterar o processo de desenvolvimento humano e qualificar a formação escolar da juventude, mesmo dentro dos limites do capitalismo, bem como a necessidade de superar o atual modo de produção da vida, persistem nessas circunstâncias.

Em situações adversas como a atual, onde a direção do processo educacional está sob forte domínio de forças conservadoras, Saviani (2003) sugere promover estratégias de resistência ativa. Nessa perspectiva, demandaria a formação de uma frente ampla, envolvendo diversos sujeitos individuais e coletivos, de diferentes setores implicados; e a apresentação/defesa de uma proposta alternativa que supere as problemáticas enfrentadas.

Por suposto, a proposta pedagógica alternativa à hegemônica, que por sua vez esteja articulada ao projeto histórico da classe trabalhadora, deve se concentrar, obviamente sem abrir mão de outras reivindicações históricas, (1) na defesa da escola pública com gestão pública e (2) na elevação do padrão cultural dos trabalhadores, justamente por serem esses os dois pilares mais atacados pelos capitalistas na atualidade.

Por fim, a categoria escola da transição (SANTOS JÚNIOR, 2018) pode oferecer instrumentos teóricos para se enfrentar os desafios e avançar na disputa pela materialização das propostas contrahegemônicas. Nesse caso, reinvindicações são colocadas como transitórias, como elementos mediadores, entre os polos realidade e possibilidade, entre o programa mínimo e o programa máximo, ou seja, entre aquilo que já temos, a educação como ela é hoje, e aquilo que ela pode ser nos limites da sociedade de classe. Portanto, são medidas, ações, propostas, bandeiras defendidas, tanto de caráter imediato quanto mediato, mas que são factíveis e concorrem para a elevação do padrão cultural da juventude.

\section{Referências}

BELTRÃO, J. A. Novo ensino médio: o rebaixamento da formação, o avanço da privatização e a necessidade de alternativa pedagógica crítica na educação física. 2019. 267 f. Tese (Doutorado em Educação) -Faculdade de Educação, Universidade Federal da Bahia, Salvador, 2019. 
BELTRÃO, J. A.; TAFFAREL, C. A ofensiva dos reformadores empresariais e a resistência de quem defende a educação pública. Retratos da Escola, Brasília, v. 11, n. 21, p. 587-601, jul./dez. 2017.

BEZERRA FILHO, J. M. Exposição de motivos da Reforma do Ensino Médio n. 84/2016/MEC. Medida Provisória n. 746 de 22 de setembro de 2016.

BOITO JR., A. Reforma e crise política no Brasil: os conflitos de classe nos governos do PT. Campinas, SP: Editora Unicamp / São Paulo, SP: Editora Unesp, 2018.

BRASIL. Lei $\mathbf{n}^{\mathbf{0}} \mathbf{1 3 . 4 1 5}$, de 16 de fevereiro de 2017. Altera as Leis $\mathrm{n}^{\circ}$ 9.394, de 20 de dezembro de 1996 e 11.494, de 20 de junho de 2007, e a Consolidação das Leis do Trabalho - CLT. In.: Diário Oficial da União, 17 de fevereiro de 2017, pp. 1-3.

BRASIL. MINISTÉRIO DA EDUCAÇÃO. Base Nacional Comum Curricular. Educação é Base Ensino Médio. MEC: Brasília, 2018a. Disponível em: http://basenacionalcomum.mec.gov.br/wpcontent/uploads/2018/12/BNCC_19dez2018_site.pdf. Acesso em: 02 de fevereiro de 2019.

BRASIL. MINISTÉRIO DA EDUCAÇÃO. CONSELHO NACIONAL DE EDUCAÇÃO. Câmara de Educação Básica (CEB). Resolução CNE/CEB n. 3, de 21 de novembro de 2018. Atualiza as Diretrizes Curriculares Nacionais para o Ensino Médio. Diário Oficial da União, Brasília, 22 nov. 2018b, seção 1, pp. 21-24.

DUARTE, N. Vigotski e o “aprender a aprender”: crítica às apropriações neoliberais e pós-modernas da teoria vigotskiana. $3^{a}$ ed. Campinas/SP: Autores Associados, 2004.

HARVEY, D. 17 Contradições e o fim do capitalismo. São Paulo: Boitempo, 2016.

LENIN, V. I. O Imperialismo, fase superior do capitalismo. Brasília: Nova Palavra, 2007.

MARX, K. O Capital: crítica da Economia Política. Livro I. 32ª edição. Rio de Janeiro: Civilização Brasileira, 2014.

MARX, K. Contribuição à crítica da economia política. 2a ed. São Paulo: Expressão Popular, 2008.

MARX, K. Miséria da filosofia: resposta à Filosofia da miséria, do Sr. Proudhon. São Paulo: Expressão Popular, 2009.

MONTORO, X. A. La Necesidad Del Marxismo para Comprender el Significa do Histórico de la Crisis. In.: CORSI, F. L.; ALVES, G. Crise do Capitalismo Global: O Capital e Suas Contradições. Bauru: Editora Praxis, 2018.

MONTORO, X. A. Capitalismo y Economía Mundial: bases teóricas y análisis empírico para la comprensión de los problemas económicos del siglo XXI. Madrid: Instituto Marxista de Economía, 2014.

MOTTA, V. C.; LEHER, R.; GAWRYSZEWSKI, B. A pedagogia do capital e o sentido das resistências da classe trabalhadora. Brasilia, Ser Social, v. 20, n. 43, p. 310-328, jul.-dez. 2018.

OIT. World Employment and Social Outlook: Trends 2017. International Labour Office - Geneva: ILO, 2017.

OLIVEIRA, R. P. A transformação da educação em mercadoria no Brasil. Educ. Soc., Campinas, v. 30, n. 108 , p. $739-760$, out. 2009.

OXFAM. A distância que nos une: um retrato das desigualdades brasileiras. Editoração: Brief Comunicação, 2017.

PAULO NETTO, J.; BRAZ, M. Economia política: uma introdução crítica. $8^{a}$ ed. São Paulo: Cortez, 2012.

PERET, E. Desemprego atinge 14 milhões de pessoas em abril. Agência de Notícias IBGE, 31/05/2017. Disponível em: https://agenciadenoticias.ibge.gov.br/agencia-noticias/2012-agencia-denoticias/noticias/10000-desemprego-atinge-14-milhoes-de-pessoas-em-abril. Acesso em 16 de novembro de 2018.

PINTO, E. C.; PINTO, J. P. G.; SALUDJIAN, A.; NOGUEIRA, I.; BALANCO, P.; SCHONERWALD, C.; BARUCO, G. A Guerra de Todos Contra Todos: a crise brasileira. Instituto de Economia da UFRJ. 
Disponível em: < http://www.ie.ufrj.br/images/pesquisa/publicacoes/discussao/2017/tdie0062017pintoet-al.pdf $>$. Acesso em 20 de julho de 2017.

RAMOS, M.; FRIGOTTO, G. Medida provisória 746/2016: a contra-reforma do ensino médio do golpe de estado de 31 de agosto de 2016. Revista HISTEDBR On-line, Campinas, n. 70, p. 30-48, dez. 2016.

SANTOS JÚNIOR, C. L. A pedagogia histórico-crítica e o papel da escola e do professor: elementos para pensar a escola da transição. Pedagogia histórico-crítica: legado e perspectivas. Uberlândia: Navegando Publicações, 2018.

SAVIANI, D. A nova lei da educação: trajetória, limites e perspectivas. $8^{a}$ ed. Campinas/SP: Autores Associados, 2003.

SAVIANI, D.; DUARTE, N. Prefácio. In.: SAVIANI, D.; DUARTE, N. (Orgs.). Pedagogia HistóricoCrítica e luta de classes na educação escolar. Campinas-SP: Autores Associados, 2012.

UNESCO. Reforma da educação secundária: rumo à convergência entre a aquisição de conhecimento e o desenvolvimento de habilidade. Brasília: UNESCO, 2008.

WORLD BANK. Learning for All: Investing in People's Knowledge and Skills to Promote Development - World Bank Group Education Strategy 2020. World Bank, 2011.

\footnotetext{
Notas:

${ }^{1}$ Esta pesquisa recebeu apoio da Fundação de Amparo à Pesquisa do Estado da Bahia - FAPESB.

2 Celi Nelza Zülke Taffarel Departamento III - Educação Física da FACED UFBA, Professora Titular Pesquisadora 1 D do CNPq. Iniciou estudos de Graduação em Educação Física na Universidade Federal do Rio Grande do Sul (UFRGS, 1974) e concluiu na Universidade Federal de Pernambuco (UFPE, 1976). Estudou também no Curso de Filosofia da Universidade Católica de Pernambuco (1977-1978). Possui especialização em Ciências do Esporte pela Universidade Federal de Pernambuco (1981), mestrado em Ciência do Movimento Humano pela Universidade Federal de Santa Maria (1982), doutorado em Educação pela Universidade Estadual de Campinas (1993) e pós-doutorado pela Universitat de Oldenburg, Alemanha (1999). Atuou em Seminários Internacionais, sob a Coordenação do Intercâmbio Acadêmico com o Professor Dr. Reiner Hildebrandt-Straman da Universidade de Braunschweg, em instituições de Portugal, Espanha e Alemanha. Pesquisadora Nível 1 do CNPq. Diretora da Faculdade de Educação da UFBA (Gestão 2008 a 2011). Foi Presidente do Colégio Brasileiro de Ciências do Esporte (CBCE) por duas gestões (1987-1989; 1989-1991). Compôs direção do ANDES-SN no bloco da Tesouraria (2000-2002) e exerceu a função de Secretaria Geral do ANDES-SN (2002-2004). É professora Titular da FACED/UFBA, ex-coordenadora do Curso de Licenciatura em Educação Física da FACED/UFBA. Coordenou o Primeiro Curso de Metodologia do Ensino e da Pesquisa em Educação Física, Esporte e Lazer da FACED/UFBA e, atualmente, é coordenadora do Curso Especial de Licenciatura em Educação do Campo da FACED/UFBA, http://www2.faced.ufba.br/educacampo, projeto piloto no Brasil, juntamente com as Universidades UnB, UFMG, UFS, UFBA. Atuou no Curso de Pedagogia da Terra, no Centro de Formação do MST Carlos Marighella no extremo sul da Bahia. Coordenou o Projeto de Elevação de Escolarização de Trabalhadores Rurais Sem Terra pelo PRONERA na FACED/UFBA (2003-2005). Representa a UFBA no Colegiado estadual do PRONERA da Bahia (2008-2011). Participa da coordenação do Grupo de Pesquisa LEPEL/FACED/UFBA http://www.lepel.ufba.br/rede.htm, e da REDE LEPEL nordeste que integra Grupos da UFPb, UFRPE, UFAL, UFS, UFRB, UEFS, juntamente com o professor Dr. Claudio de Lira Santos Júnior (2000-2011). Coordena o Pólo da REDE CEDES - Centro de Desenvolvimento do Esporte Recreativo e de Lazer, relacionado com $\quad 0 \quad$ LEPEL/FACED/UFBA http://www.faced.ufba.br/redecedesufba/redecedesufba2index_arquivos/page0001.htm, e o Pólo de Referência em Educação do Campo da UFBA. Contribuiu com a formação de 80 pós-graduandos, especialistas, mestres e doutores e publicou mais de 200 textos em livros, periódicos. Em meios eletrônicos são, aproximadamente, 245 textos publicados http://www.rascunhodigital.faced.ufba.br/ com mais de 27 mil acessos. Coordena atualmente a pesquisa sobre Diagnóstico Nacional do Esporte. Tem experiência acumulada no exercício da docência, na realização de pesquisas e de atividades de extensão em duas grandes linhas: Educação Física, Esporte e Lazer, com ênfase em: Trabalho Pedagógico; Epistemologia, Metodologia do Ensino e da Pesquisa, Produção do conhecimento científico em Educação Física, Esporte e Lazer; Políticas Públicas de Esporte e Lazer; Ensino e Aprendizagem em conteúdos específicos do Esporte e da Ginástica; Projeto Político Pedagógico, Currículo e Diretrizes Curriculares para a Educação Física, Esporte e Lazer. Educação, com ênfase na Educação do Campo, atuando na Escola do Campo, na Formação de Professores para a Escola do Campo - Licenciatura em Educação do Campo, na produção do conhecimento sobre Educação do Campo, Políticas Públicas para a Educação do Campo, projeto político pedagógico e trabalho pedagógico, na Educação do Campo. É Militante cultural, internacionalista, da IV Internacional Reproclamada, colaborando com movimentos de luta social da classe trabalhadora - nos sindicato, no partido e, em movimentos de trabalhadores, Sem Terra (MST) e Desempregados (MTD). Endereço: FACED. ORCID: Email: taffarel@ufba.br

3 Professor Adjunto do Centro de Formação de Professores da UFRB. Doutor em Educacao pelo PPGE FACED UFBA. ORCID: Email: arleneducacaofisica@ufrb.edu.br

${ }^{4}$ Segundo a Oxfam, desde 2015, o 1\% mais rico da população mundial detém a mesma riqueza do resto do planeta, e 8 pessoas concentram em suas mãos a riqueza equivalente de outros 3,6 bilhões (OXFAM, 2017). No Brasil a situação não é diferente, os
} 
6 homens mais ricos detêm uma fortuna equivalente ao patrimônio de metade da população mais pobre do país, cerca de 100 milhões de pessoas (CONGRESSO EM FOCO, 2017).

5 Ao invés de fazer menção ao governo específico, adotou-se a opção de fazer referência ao bloco no poder. Nesse sentido, mesmo reconhecendo que há diferenças entre o governo Michel Temer e o governo que se inicia de Jair Bolsonaro, entende-se que o país continua a ser governado pelas mesmas frações da burguesia, tendo a hegemonia da burguesia associada ao capital internacional. Nesse processo, "a grande burguesia interna foi atraída para o campo político da burguesia associada ao capital internacional e poderá, no limite, dissolver-se enquanto fração autônoma de classe" (BOITO JR., 2018, p. 275). Ainda, em relação ao conceito de bloco no poder, este trabalho está fundamentado em Boito Jr. (2018). O referido autor destaca que este conceito tem algumas características que devem ser mencionadas. "Em primeiro lugar, ele contempla a assimetria existente nas relações entre as classes sociais: o bloco no poder é composto apenas pelas classes dominantes e suas frações. Assim, tal conceito distingue a posição ocupada pelas classes dominantes no processo político, que é a posição das classes sociais cujos interesses históricos são organizados pelo Estado, da posição que cabe às classes trabalhadoras. Em segundo lugar, o conceito de bloco no poder permite pensar as relações de unidade e de luta que aproximam e opõem os interesses das frações da classe dominante, tornando-se instrumento fundamental para explicar grande parte dos conflitos político que não são, necessariamente, conflitos que opõem a burguesia aos trabalhadores. Em terceiro lugar, esse conceito nos dá um critério para pensar a hierarquia de poder existente entre as diferentes frações da burguesia. Ele comporta a noção de fração hegemônica, que é a fração cujos interesses são priorizados pela política econômica do Estado mesmo quando essa priorização fira interesses das demais frações do bloco no poder. Por último, no plano da análise da política externa, o conceito de bloco no poder permite superar as falhas mais evidentes da corrente teórica realista, que domina os estudos de relações internacionais, ao possibilitar que se conceba a política externa de um Estado determinado como o prolongamento, no cenário internacional, do arranjo interno de poder e especificamente como prolongamento dos interesses da fração hegemônica. O conceito de bloco no poder permite, portanto, discernir os vínculos estreitos que existem entre a política nacional e a internacional e detectar o conteúdo real - de classe - daquilo que os realistas denominam 'interesse nacional' e que o discurso ideológico sugere ser o interesse de todo o povo" (BOITO JR., 2018, p. 157).

${ }^{6}$ Estudantes de vários lugares do Brasil ocuparam escolas como forma de protesto contra essa reforma. Segundo a UBES (União Brasileira dos Estudantes Secundaristas), em 28/10/2016 tínhamos 1.197 escolas ocupadas. Disponível em: http://ubes.org.br/2016/ubes-divulga-lista-de-escolas-ocupadas-e-pautas-das-mobilizacoes/. Acesso em 10 de fevereiro de 2017.

${ }^{7}$ Das cinco audiências públicas agendadas para se discutir a BNCC do ensino médio, as audiências em Belém/PA e em São Paulo/SP foram canceladas em função de protestos. As demais (Florianópolis/SC, Fortaleza/CE e Brasília/DF) ocorreram sob duras críticas e a participação de professores e sindicalistas foi dificultada.

8 Dados noticiados no seguinte link: < https://g1.globo.com/economia/noticia/kroton-fecha-compra-da-somos-educacao-por-r46-bilhoes.ghtml>. Acesso em 18 de novembro de 2018. 